\title{
E-UNIVERSITY FOR STRATEGIC PLANNING OF REGIONAL SYSTEM OF ENGINEERING EDUCATION
}

\author{
Irina Belinskaia ${ }^{1}$, Sergey Sergeev ${ }^{2}$, Tatyana Sidnenko ${ }^{1}$ \\ ${ }^{1}$ Leningrad State University named after Alexander Pushkin, Russia; ${ }^{2}$ Peter the Great Saint-Petersburg \\ Polytechnic University, Russia \\ belinska@yandex.ru, sergeev2@yandex.ru, sidnenko@list.ru
}

\begin{abstract}
One of the current stage development strategic tasksfor engineering education is the creation of "supporting" universities in the Russian Federation regions. In the context of socio-economic relationsdigitalization, the role of information technology in the process of forecasting the regional educational structure parameters is growing. This action is important at the stage of their forming, as well as for the organization of strategic and operational planning. The application of a multidisciplinary approach to the process of training engineering personnel necessitates the development of mechanisms for a convergent educational environment, which is based on the principles of network partnership. The solution to this problem is based on the introduction of experimental regional sites in the format of the "Electronic University", which allows the most optimal way to satisfy both the needs of the manufacturing sector in training qualified specialists and potential consumers of educational services. The aim of the presented scientific article is to develop a methodology based on the transformation of professional activities in the field of experience in applying a multidisciplinary approach to the principle of feedback from consumers of educational services, as well as interaction with subjects of the educational process. As an object of study, we consider educational programs of engineering profile of Peter the Great St. Petersburg Polytechnic University, studied from the point of view of their dynamic performance. Achieving this goal is realized using stochastic optimization methods, the mathematical theory of finding solutions in the face of uncertainty, and computer modeling. As a result of the study, the impact areas of digitalization on the conceptual updating of the educational process content are ranked, the level of mutual influence of the labor market needs and the competence model of training engineering personnel in the digital economy is identified.
\end{abstract}

Keywords: electronic university, engineering education, mathematical modeling, digital economy, regional development, innovative platforms, cross-methods.

\section{Introduction}

The solution to the issue of creating an effective institutional environment (system) for regional development largely depends on the chosen strategy for regional management of socio-economic development [1]. The basic condition is a comprehensive and interrelated improvement of the interaction mechanism between state, public and educational institutions in the process of creating an institutional environment and improving the efficiency of the market economy. Incentive and support for institutional innovation should be provided at all levels: national-state, regional-industry, municipal and private. This requires the openness of information flows and the creation of an effective feedback mechanism. A comprehensive assessment of investment activity in the region is impossible without a deep analysis of the main resource - the human resources potential of the regions.

The study of the mechanism for building a modern model of personnel support for high-tech enterprises actualizes the problems of applicability of methods for evaluating the effectiveness of educational programs of higher education institutions. A significant groundwork in considering the problem of building infrastructure mechanisms for implementing and analyzing the effectiveness of online learning in the context of digitalization was made by domestic and foreign researchers: $\mathrm{M}$. Porter, L. Borisoglebskaya, G. Egorova, V. Kostin, L. Lapidus, I. Nasyrov, T. Sidnenko. William T. Pink, George W. Noblit, A. Grigoriev, I. Belinskaya, S.Bolshakov, A.Melnikov and E. Tikhonova achieved significant results in assessing changes in the context of analyzing the specifics of relationships between economic system entities.

William T. Pink and George W. Noblit achieved significant results in assessing changes in the context of analyzing the specifics of relationships between economic system entities. A. N. Grigoriev, I. V. Belinskaya, S. N. Bolshakov, A. S. Melnikov, E. Yu.Tikhonova revealed that the need for state management of regional socio-economic development is largely due to the imperfection of the market mechanism and its inability to solve modern problems of development at the state and regional levels. A comparative analysis of the implementation indicators performance of AIS in the education management system at the present stage is presented in the works of Kusimo A. C., Thompson M. E., 
Atwood S. A., Sheppard S. The review of the advantages of digitalization of the educational process is justified by L. V. Lapidus and T. I. Sidnenko. Cluster analysis of regional needs for qualified personnel in the context of the economy digitalization in the context of the educational innovation strategies developmentwas studied by Barry B. E, Ohland M. W, Mumford K. J, Long R. A. At the same time, at the present stage, the issues of both the potential for the development of convergent educational environments and destructive processes that affect the quality of engineering education and the competence of personnel are not sufficiently disclosed.

The key problem, in our opinion, is to identify the factors and methodological foundations of implementing experimental regional platform effectiveness in the format of an "Electronic University". Solutions to this problem are based on a multidisciplinary approach to the process of training, comparative analysis of network partnerships performance indicators, identify matching needs of the manufacturing sector in the training of qualified specialists, the demand of educational services potential consumers. The approach to evaluating innovations from the point of the chosen strategic management view, based on the study of knowledge management as a system, is based on the fundamental principles of the nonlinear integrated model.

Thus, the research aims: to develop methodological bases for managing the transformation of professional activities based on the principles of feedback with consumers of educational services and electronic interaction of educational process subjects; to consider the management of the professional activities transformation in a network partnership in the framework of digital interaction between consumers of educational services and universities; to identify the dynamic effectiveness of the experimental regional platforms introduction in the format of an "Electronic University".

Management of professional activity transformation is based on the application of a multidisciplinary approach to building a convergent educational environment. In our opinion, the formation of competence centers in the field of digital transformation and innovation platforms is a key mechanism for training personnel. An important direction and source of development is the system of higher engineering education. Today, the discrepancy between the qualification opportunities of graduates and the needs of business is obvious. Some industries, such as agricultural engineering, transport and logistics, and resource extraction, are experiencing a shortage of workers with the necessary skills, while in other areas there is an oversupply of labor resources.

The practice of successful knowledge management in the world has formed the basis for the possibility of introducing advanced intellectual technologies into the educational environment of the Saint Petersburg State Polytechnic University. The advantages of the proposed model of "Electronic University" as an innovative institutional environment are shown at the stage of searching for applicants. Namely, their inclusion in the industry system based on the development of the engineering services sphere regulation elements using the mechanism of intra-industry remote interaction. In addition, the model serves as a tool for improving the infrastructure of training state regulation in the region. Obvious system advantages of the "Electronic University" model: non-linearity, multiplicity of events in the innovation cycle; adaptability and variability of management growth strategies; network nature of interaction of economic functions, interinstitutional interactions of the information flow.

At the same time, the disadvantages of the model, according to the authors, are a rather long process of infrastructure planning and implementation, the lack of a regulatory framework regulating the large-scale use of AIS in the conditions of educational program variability and services.

\section{Materials and methods}

The object of the research is considered educational programs of engineering training at the Saint Petersburg Polytechnic University of Peter the Great from the point of their dynamic performance view . The goal is achieved using mathematical and computer modeling methods. The conceptual basis of the research is the theoretical and methodological works of domestic and foreign researchers on the management of institutional transformations in higher education, as well as the experience of implementing a convergent educational environment.

The prevailing research methods are approaches based on the analysis of educational needs, based on the deferred demand model [2], cross-functional analysis of the educational services market volume [3], cluster analysis of the territory and regional labor market [4], methods for analyzing the 
reproduction of human capital in the system of additional education [5]. Issues of risk analysis and decision-making in conditions of uncertainty are solved by the methods of the operations research theory. The systematic nature of the educational organization modernization determines the wide variability of the content of educational programs. Since today's young people, who are potential entrants, are overwhelmingly focused on the Internet resources, it is necessary to attract opportunities for digital information exchange to solve the task set in this study.

\section{Results and discussions}

Analysis of the market situation in the field of educational services is necessary primarily to assess the prospects for attracting applicants to an educational institution in conditions of uncertainty. Currently, the prevailing factor is the aggravation of competition for existing niches of offers and volatility. The starting point is to make management decisions [6] in education, taking into account the balance of multidirectional indicators. In the standard approach, when considering the consequences of incomplete information [7], a mathematical model is constructed [8], and calculations are performed on linear functions. The practical meaning of these results is complicated by the fact that linearization is only possible in the vicinity of an equilibrium that is not known in advance. This, of course, is not suitable for the search and development of specific management, infrastructure, technical and economic recommendations for the market strategy of educational institution management . The problem is particularly acute in relation to engineering education [9]. The launch of digital platforms in the field of training allows to implement algorithms for selecting future students. It is necessary to develop an algorithm based on a mathematical model that allows not only to process big data on the preferences of applicants, but also to provide a scientifically based optimization of the curriculum and best organize the educational process in a dynamic competitive market environment for providing educational services.

In general, the preliminary data $W$ obtained from such major search engines [1] as Yandex, Google and others will present as a set of vectors:

$$
W_{i}=\left\{p_{i}, D_{1}, D_{2}, \ldots, D_{N}\right\},
$$

where $p_{i}$-percentage of potential pool of applicants, $i=1,2, \ldots, M ; \Sigma p_{i}=1$;

$M$ - number of study groups;

$D_{k}$ for $k=1,2, \ldots, N$ - name (type) of the discipline or group of disciplines offered for study;

$N$ - number of subjects for which educational activity is allowed.

From these data we can create a matrix that reflects the statistics of preferences for the choice of desired professional competencies

$$
P=\left\{p_{i j}\right\},
$$

where $i, j=1,2, \ldots, N$ - elements which show the share of preferences for choosing $i$ subject $j$.

The methods chosen by the authors [10] eventually allowed us to form a system of parameters for information search and implementation of an Electronic University within the framework of the integrated educational system concept that take into account the need for engineering personnel. The experience of these studies has led to the following result: the proposed concept paper on leading indicator management, infrastructure development, maintenance of the educational process taking into account the interdependence of the needs of the regional labor market and the competence-based model of training engineers in the digital environment.

We demonstrate the order and algorithm [11] of the solution on a problem of bounded dimension. During the campaign to attract applicants to study engineering at the Polytechnic University, a survey was conducted among potential students. It was suggested to arrange their desire to get special knowledge in four areas of training: engineering of transport and technological systems; mechanical engineering technology; virtual engineering technology; robotics. The obtained statistical data in these areas are formalized as a correspondence $D_{k}$ for $k=1,2,3,4$. Let us write the vectors $W_{i}$. Their components are indicators of students' interest in disciplines in descending order of preferences. Since in modern conditions of digital technology penetration the data required for calculation can be 
obtained online, calculations can be performed in real time, which will allow to switch to planning in the modern system the leading [12] indicators. In the result we got [13] the following data:

$$
\left.\begin{array}{c}
W_{1}=\left\{6 \%, D_{4}, D_{3}, D_{2}, D_{1}\right\} \\
W_{2}=\left\{19 \%, D_{3}, D_{2}, D_{1}, D_{4}\right\} \\
W_{3}=\left\{32 \%, D_{2}, D_{1}, D_{4}, D_{3}\right\} \\
W_{4}=\left\{43 \%, D_{1}, D_{4}, D_{3}, D_{2}\right\}
\end{array}\right\}=\left|\begin{array}{cccc}
* & 1-p_{21} & 1-p_{31} & 1-p_{41} \\
p_{21} & * & 1-p_{32} & 1-p_{42} \\
p_{31} & p_{32} & * & 1-p_{43} \\
p_{41} & p_{42} & p_{43} & *
\end{array}\right|,
$$

Note that the condition for completeness of the event group (the sum $p_{i}$ is equal to one for $M=4$ ) is met. Computer processing allows to build a complete preference matrix $P$, when $p_{i j}$-is the degree of preference of the discipline $D_{i}$ before $D_{j}, i, j=1,2,3,4$.

Finallywe will form the following matrix [14] according to the survey data:

$$
P=\left|\begin{array}{ccccc} 
& D_{1} & D_{2} & D_{3} & D_{4} \\
D_{1} & * & 43 \% & 75 \% & 94 \% \\
D_{2} & 57 \% & * & 32 \% & 51 \% \\
D_{3} & 25 \% & 68 \% & * & 19 \% \\
D_{4} & 6 \% & 49 \% & 81 \% & *
\end{array}\right|,
$$

The competition between two educational institutions $U_{1}$ and $U_{2}$ in the process of recruiting [15] students for training is considered. At the same time $U_{2}$ concentrates its activities on the directions $D_{1}$, $D_{3}$, and the sphere of interests $U_{1}$ lies in the directions $D_{2}, D_{4}$. In the first version of the work we can build the following representation of the problem.

\section{First version of the work}

Table 1

\begin{tabular}{|c|c|c|c|}
\hline \multicolumn{2}{|c|}{$\mathrm{V} 1$} & \multicolumn{2}{c|}{$U_{1}$} \\
\cline { 3 - 4 } & $D_{1}$ & $43 \%$ & $D_{2}$ \\
\hline \multirow{2}{*}{$U_{2}$} & $D_{1}$ & $44 \%$ \\
\cline { 2 - 4 } & $D_{3}$ & $68 \%$ & $19 \%$ \\
\hline
\end{tabular}

The solution matrix [16] is used for solving a dual linear programming problem to find the Nash equilibrium. Putting the data in the computer, we get the diagram, Fig. 1a.

Enter the notation: $\alpha$ - share of discipline $D_{1}$ in the curriculum $U_{2} ; \beta$ - share of discipline $D_{2}$ in the curriculum $U_{1}$.

Then by creating a balance equation

$$
S=\beta[43 \alpha+68(1-\alpha)]+(1-\beta)[94 \alpha+19(1-\alpha)]
$$

to find a solution $\alpha^{*}$ and $\beta^{*}$, we equate the partial derivatives to zero:

$$
\frac{\partial S}{\partial \alpha}=0
$$

and

$$
\frac{\partial S}{\partial \beta}=0
$$

From here

$$
\alpha^{*}=49, \beta^{*}=75
$$

we apply the equations [17] for calculating the values $H_{1}{ }^{*}$ of the share of the University $U_{1}$ from the total mass of applicants for education and $\mathrm{H}_{2}{ }^{*}$ the share of the University $U_{2}$ :

$$
H_{1}^{*}=43 * 0.49+68 * 0.51 \approx 55.75 \% ; H_{2}^{*}=100 \%-68 * 0.75-19 * 0.25 \approx 44.25 \% \text {. }
$$

This will give the desired figures for planning activities, obtained from the distribution condition of the incoming flow. 
Now let us look at the second option, when expenses were incurred [18] to study the activities of other participants in the educational services market in order to participate in the most successful campaign to attract applicants. In this case, the task is presented as follows.

Table 2

Second version of the work

\begin{tabular}{|c|c|c|c|c|c|}
\hline \multicolumn{2}{|c|}{$\mathrm{V} 2$} & \multicolumn{4}{|c|}{$U_{1}$} \\
\cline { 3 - 6 } \multicolumn{2}{|c|}{} & $D_{1}-D_{2}$ & $D_{1}-D_{2}$ & $D_{1}-D_{4}$ & $D_{1}-D_{4}$ \\
\cline { 3 - 6 } & $D_{3}-D_{2}$ & $D_{3}-D_{4}$ & $D_{3}-D_{2}$ & $D_{3}-D_{4}$ \\
\hline \multirow{2}{*}{$U_{2}$} & $D_{1}$ & $43 \%$ & $43 \%$ & $94 \%$ & $94 \%$ \\
\cline { 2 - 6 } & $D_{3}$ & $68 \%$ & $19 \%$ & $68 \%$ & $19 \%$ \\
\hline
\end{tabular}

In this case, the search for a solution is based on the Nash theorem. Accordingly, for $U_{1}$ we have:

$$
\underset{\text { the columns }}{\min \max }=43 \%
$$

For $U_{2}$

$$
\max _{\text {strings }} \min =43 \%
$$

This means that the educational institution $U_{2}$ needs maximum attention be paid to the development of education $D_{1}$, in turn, the education institution $U_{1}$, based on the information received about the activities of another, needs maximum of attention to development education in the set of disciplines $D_{2}$.

In the third variant, a more complex picture is observed. Since during the first period (academic year) an analysis of activities is carried out, then, accordingly, a part of potential students in the volume $r$ percentages will be interested in other offers of $U_{2}$ from lost to $U_{1}$. At the same time, the task of determining the share of interested parties in training has the form:

Table 3

Third version of the work

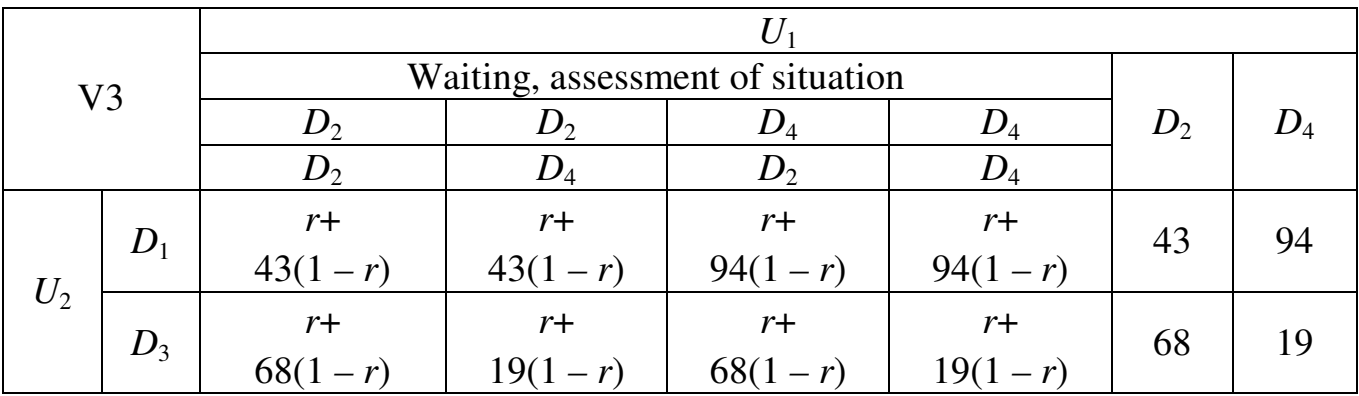

Setting as a numerical example $r=20 \%$ we put the data in the computer and get the diagram Fig. 1b:
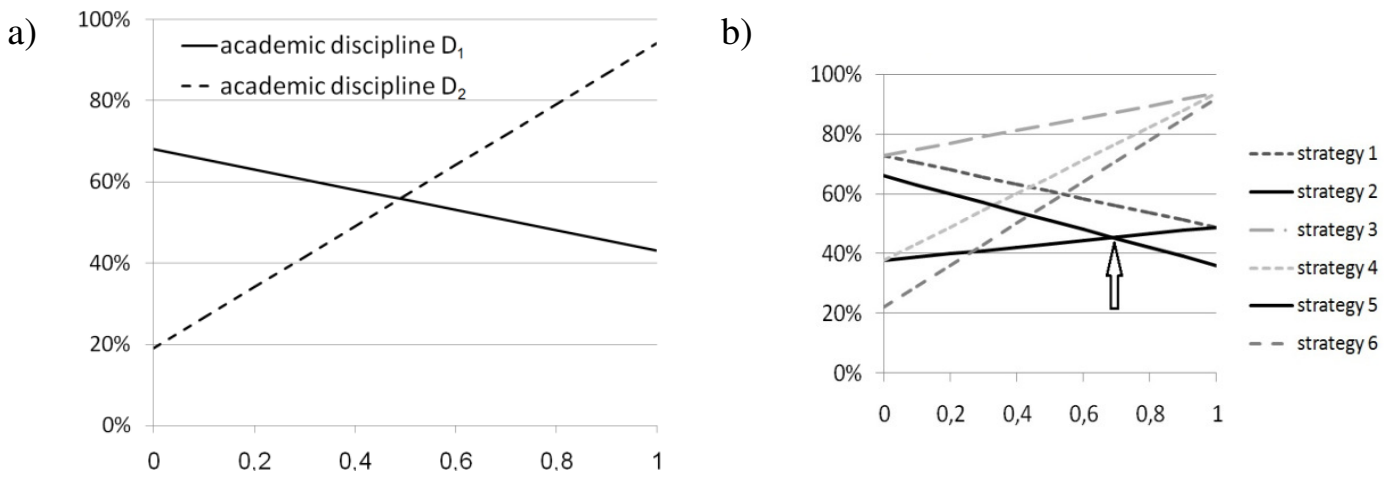

Fig. 1. Finding solutions process (a) and Solution diagram for option 3 (b)

In Figure 1b, the arrow mark the Nash equilibrium option that gives the desired solution. To find it, we need to solve the equation: 


$$
0.544 \alpha+0.352(1-\alpha)=0.43 \alpha+0.68(1-\alpha)
$$

where we get

$$
\alpha^{*} \approx 0.749 \text {. }
$$

Now we can define the values $H_{1}{ }^{*}$ of the institution's share $U_{1}$ :

$$
\begin{gathered}
H_{1}^{*}=0.544 \cdot 0.749+0.352 \cdot(1-0.749) \approx 49.58 \%, \\
H_{2}^{*} \approx 50.42 \% .
\end{gathered}
$$

We can put the results in a table:

Distribution of the applicants interested total number in the educational programs

\begin{tabular}{|c|c|c|c|}
\hline Share & Option 1 & Option 2 & Option 3 \\
\hline$U_{1}$ & $55.75 \%$ & $43 \%$ & $49.58 \%$ \\
\hline$U_{2}$ & $44.25 \%$ & $57 \%$ & $50.42 \%$ \\
\hline
\end{tabular}

The data presented in the table show the distribution of the applicants interested total number in the educational programs of competing educational institutions. Note that all the arguments, as well as mathematical formalisms, were based on statistics of educational services consumers preferences of the Saint Petersburg State Polytechnic University in comparison with universities of the Russian Federation that implement engineering education.

\section{Conclusions}

In the modern concept of higher education, the priority is the dynamic formation of educational programs that meet the interests of both business and students, who want to implement the acquired competencies in their future work. The research conducted by the authors on the problems of personnel training, as well as the experience of implementing the online education model, allowed us to draw the following conclusions:

1. The success of the engineering training system transformation depends on the relationship of educational programs with the needs of business and the regional labor market.

2. The capabilities of Web 4.0 networks provide extensive feedback material that allows to collect statistics on the preferences of future students, segmenting them by a number of characteristics, such as geography, age, date of graduation from high school, range of interests, and other information.

3. The use of mathematical models and artificial intelligence systems will allow to make optimal management decisions in the process of planning the work of the University from an economic point of view and take into account the requirements of the educational services market.

\section{References}

[1] Project management of social and economic development the Leningrad region-Saint Petersburg. - SPb: The Leningrad State University named after A. S. Pushkin, 2020. 270 p.

[2] Kusimo A. C., Thompson M. E., Atwood S. A., Sheppard S. Effects of Research and Internship Experiences on Engineering Task Self-Efficacy on Engineering Students Through an Intersectional Lens. Proceedings of the ASEE Annual Conference \& Exposition, 2018, pp. 1-19.

[3] National Research Council. Engineering Education: Designing an Adaptive System. Washington, DC: The National Academies Press, 1995.

[4] Barry B.E., Ohland M.W., Mumford K.J., Long R.A. Influence of Job Market Conditions on Engineering Cooperative Education Participation', Journal of Professional Issues in Engineering Education \& Practice, vol. 142, no. 3, 2016, pp. 1-8.

[5] Sidnenko T. System approach to the development of the Agro-industrial complex personnel potential // Development of educational programs agricultural profile professional and public accreditation system in the Russian Federation. "Development of Public Accreditation of Agricultural programs in Russia (PACAgro)" (543902 - TEMPUS - 1-2013-1-SK-TEMPUSSMGR): SPb: SPbSAU, 2017. pp. 108-116.

[6] Lapidus L. The Digital economy. E-business and e-Commerce management. 2009. 479 p. 
[7] Sergeev S., Sidnenko T. Multidisciplinary convergence of information educational tools // Izvestiya Sankt-Peterburg State Agrarian Univesity - SPb.SPbSAU, 2015, pp. 88-96.

[8] National Academy of Engineering. 2005. Educating the Engineer of 2020: Adapting Engineering Education to the New Century. Washington, DC: The National Academies Press.

[9] Regional standard for industrial growth staffing [online][11.02.2020] Available at: http://togirro.ru/assets/files/CNPO/kadry/Standart_KPR_upd.pdf

[10] Abramyan G. Investment and credit model of the high-tech higher education organization in the context of labor markets and production globalization. /G. Abramyan, G. Katasonova // Modern science-intensive technologies. 2016. Vol. 8-2. pp. 275-279

[11]Belinskaia I., Chaikovskaia A., Frolova N. 2019 Devepopment of management mechanisms for forming investment climate in border region. // Scientific and technical Bulletin of the Saint Petersburg State Polytechnic University. Economics. 12. Vol. 2. pp. 52-62.

[12] Bogdanchikova T., Sidelzev V. About the role of Omsk state technical University in the training of engineering personnel in the Omsk region / / Creative economy. Publisher: BIBLIOGLOBUSP ublishing house (Moscow). Issue 12.Vol. 11. 2018. pp. 1885-1894.

[13] The action plan for the direction "Formation of research competencies and technological reserves", approved by the Government Commission on the use of information technologies to improve the quality of life and business conditions (Protocol No. 2 of December 18, 2017), within the framework of the program "Digital economy of the Russian Federation" (Order of the Government of the Russian Federation No. 1632-R of July 28, 2017).

[14] Order of the Ministry Education and Science Russian Federation 23.06. 2009 N 218 "About the approval of the Order of creation and development of innovative infrastructure in the field of education" [online][11.02.2020] Available at: https://rg.ru/2009/08/20/innovacii-obrazovaniedok.html

[15] International Handbook of Urban Education. 2017 / Edited by William T. Pink, George W. Noblit. - Dordrecht: Springer1363 p.

[16] Lozano E. Density in communities, or the most important factor in building urbanity.2013 In: Larice M., Macdonald E. (eds) Urban design reader. Secondedition. (London; NewYork: Routledge). pp. 399-414.

[17] Gukov A., Papanova S., Plotnikov S., Fominnih M. 2018 Influence of education on labor remuneration in the modern economy // Journal of economic theory. Vol. 15-1.- pp. 49-56.

[18] Porter M.E. Local clusters in a global economy. // Hartley J. (ed) Creative industries. - Malden, Oxford: Blackwell publishing, 2005. pp. 260-265. 